\section{Revelaciones sobre la forma de la ciudad}

\section{Carles Crosas}

"F orma Urbis: cinco ciudades bajo sospecha" es un título cipar su contenido, insinúa en la elección de unas pocas palabras, cuál será su tono general. Por un lado está la recurrencia al lenguaje de la criminología ("bajo sospecha”), una suerte de manifiesto de la voluntad de alejarse de la común ambivalencia del lenguaje de la arquitectura y el urbanismo. Y acentuando la intriga del relato, convertir en cuestión objetivable, la vehemencia de sus argumentos. Porque en nuestro ámbito disciplinar hay una tendencia repetida a enmascararlo todo con una áurea de misterio, y demasiado a menudo, se acaba el cuento sin saber exactamente cuál fue el delito, ni quién detuvo el ladrón.

Pero incluso nuestro Pepe Carvalho tiene sus debilidades, amante como es de la ciencia tanto como del pensamiento. Y no se conforma en resolver sus sospechas, sino que persigue ma urbis, la auténtica luz que guía su espíritu. A estas alturas y ma urbis, la autentica luz que guia su espiritu. A estas alturas y en nuestro contexto más próximo, razonar sobre la "forma urbano lo es desde la perspectiva que sostiene el autor.

“¿Es la sospecha una idea a priori?” ¿Son las ciudades una elección para demostrar algo que se ha descubierto antes? se pregunta Antoni Marí y añade "Pero, ¿es la sospecha de qué? ¿de que el proyecto de cada ciudad se ha ido alejando de un cierto principio originario por las distintas alternaciones que sufre la ciudad de una forma más o menos arbitraria?". ¿O es que a la vista de los cinco "cadáveres" se llegarán a reconstruir las razones de un crimen en cadena?"

El autor explica cómo el recorrido del libro arranca en Trieste, la bella ciudad del Adriático que cautivó su atención durante un tiempo. Lo que empezara como un viaje intelectual desencadenado en la curiosidad de un estudiante de arquitectura de
la ETSAB a mediados de los $70^{\prime}$ - que la descubrió a partir de la ETSAB a mediados de los 70' - que la descubrió a partir de
un proyecto de Luciano Semerani - acabaría siendo después un proyecto de Luciano Semerani - acabaría siendo despues una exp
cludad $^{\mathrm{i}}$.

Pero también en el libro está presente la extraordinaria efervescencia que vivió la disciplina postulando alternativas de acción en el panorama de la transición política española. Josep Parcerisa como participó, acompañando a su maestro Manuel de Solà-Morales, en la revisión del planeamiento contemporáneo en algunas ciudades españolas, una cuestion que sería teóricamente discutida en formatos diversos y presentado en los primeros números de la revista UR-Urbanismo Revista ". Los casos de Valladolid, Gijón, Salamanca y Tarragona, fueron aquí argumentados en un trabajo de definición disciplinar del denominado "urbanismo urbano" (definicion vigente aun, que reivindica una aproximación a la ciudad propia de los arquitectos, en contraposición al urbanismo de las leyes, el del planeamiento, el más administrativo)

Volvamos a la sección novedades. Es a partir de la inmersión en el caso de Trieste que el autor formula cómo la belleza de las ciudades es capaz de sufrir un proceso de sedimentación que en ocasiones no tiene siquiera un autor (arquitecto, político) ni un plano que la plasme, sino que es producto de una suma de intenciones, incluso carambolas. Y es este descubrimiento el que conduce a la elaboracion de su tesis doctoral "i, que investifin de demostrar la presencia del mismo fenómeno que se había desvelado en la ciudad del norte de Italia.

La narración se desgrana a través de una elaboración documental muy completa, en donde desfilan algunas novelas de referencia sobre las ciudades al lado de la crítica a los relatos históricos locales. Pero seguro que aquello que lo singulariza en relación a otras tantas publicaciones es el apoyo esencial en la expresión gráfica, algo que es tan característico de una mera de explicar (y proyectar en) la ciudad. Es así como grabados de época se entrelazan con magníficos encuadres aereos de las ciudades y como planos más ortodoxos remasterizados aparecen al lado de diagramas policromáticos y bocetos intencionados.

La narración se desgrana a través de una elaboración documental muy completa, en donde desfilan alounas novelas de referencia sobre las ciudades al lado de la critica a los relatos históricos locales. Pero seguro que aquello que lo singulariza en relación a otras tantas publicaciones es el apoyo esencial en la expresión gráfica, algo que es tan característico de una determinada manera de explicar (y proyectar en) la ciudad.

Quizás más como intuición avant la lettre que como conclusión de una investigación doctoral, el libro nos sirve una lección concreta sobre la "identidad urbanística y forma urbis". La "identien la ciudad como suma de tres aspectos: la forma de la geografía (un perfil litoral, la planicie y las vertientes, las ondulaciones de los ríos....), la vibración imparable de sus formas construidas (casas, edificios, materias) y por último, una presencia más intangible, que es algo así como "el espejo en el que se reque se asocia a la memoria de sus costumbres, algo real o quizás imaginado. Pero el mérito del libro, y así lo remarcó joan Busquets en la presentación, es cómo la forma urbis pasa de ser una simple relectura de la ciudad existente a ser
también una posibilidad proyectual de cambio. Y subraya: también una posibilidad proyectual de cambio. Y subraya: "el argumento disciplinar más relevante es el cómo el diseño de algunas piezas urbanas [no necesariamente los grandes planes generales] son capaces de generar una nueva forma de la ciudad". Es el relato de la construcción de elementos de trazado muy potente - avenidas, plazas, rondas y ramblas escala que estas capitales experimentarán. Son en su consideración, una

El intríngulis sobre la forma de la ciudad se descubre en situaciones encriptadas, lejos de los paradigmas de las nuevas ciudades y de los reconocidos proyectos que recogen los tratados de la materia (de Morris, Benevolo, Bacon, entre otros) iv. El libro se adentra en unas ciudades nada prototípicas desde este punto de vista y en una época marcadamente gris del urbanismo español (entre los años 40 y 80 del siglo XX). Y este me parece un mérito valiosísimo del libro: el de convertir en objeto de interés unos casos que sin ser atractivos a priori ni en exceso, son muy reales. Unas lineas en la introducción del libro explican sintéticamente esta intención: "[desmentir] que la forma urbis no existiera, que la ciudad contemporánea fuese un calvario de defectos, imperfecciones y casualidades. Pero [alertar] sobre el tópico contrario y complementario: que la forma urbis fuese un concepto tan restrictivo que se agotase en el anhelo de una imagen en planila cual predisponían los arquetipos habituales del imaginario del arquitecto."

Por la complejidad de situaciones que se abordan (cinco ciudades), pero también por la densidad discursiva, el libro no necesariamente debe ser leído de una vez, ni siquiera de manera continua. Más bien sugiere una lectura selectiva (empezando por Palma de Mallorca o por Tarragona, cada cuál) degustando con pausa la densidad discursiva y la cascada argumental que son pautadas en ilustrativos enunciados. La narración es de cada una de las ciudades es referida a algunos espacios de cada una de las ciudades es referida a algunos espacios concretos: al camino de Ronda en Granada, a la Alameda en Málaga, a la plaza Imperial Tarraco en Tarragona, a la avenida Lavedra en A Coruña y a la calle Jaime III en Palma. Son los faciudad, que ponderan el interés de los intentos y el mérito de los logros, que sitúan lo que había ocurrido antes y lo que pudiera haber pasado después.

Por la complejidad de situaciones que se abordan (cinco ciudades), pero también por la densidad discursiva, el libro no necesariamente debe ser leído de una vez, ni siquiera de manera continua. Más bien sugiere una lectura selectiva (empezando por Palma de Mallorca o por Tarragona, cada cuál) degustando con pausa la densidad discursiva y la cascada argumental que son pautadas en ilustrativos enunciados. Plan de González Edo que la ciudad consigue saltar el Guadalhorce en la prolongación de uno de sus espacios más caracteidas y venidas entre el Plan del 51 y los planes parciales y los idas y venidas entre el Plan del 51 y los planes parciales y los nuevos polígonos residenciales en el momen

En Granada se discute la influencia que tuvo en tiempos paraprovincial pasaría a espina dorsal urbana. Su valor como nueva directriz capaz de tensionar la ciudad del futuro topó sin embargo con los "prejucios" de la propia ciudad, resentida aún de la apertura de la Gran Vía unas décadas antes. Y a pesar de que la traza sería el polo de atracción de intereses de immobiliarios banales, el culturalismo granadino descubriría en el pasear por
la nueva amplia avenida, un nuevo punto de vista para la ciudad.

Pero la ciudad no se hace solo de calles y barrios. El libro cuenta también cómo una buena pieza arquitectónica es capaz de transformar la ciudad. Es el caso del edificio de los Juzgados de Tarragona, de Alejandro de la Sota, una obra de gran inteligencia que consigue reinterpretar el problema del lugar, la Plaza Imperial Tarraco, de una manera espectacular. Levantada la plaza, la ciudad la incorporaría en sus emblemas, y sería en adelante un contrapunto interesante en la discusión sobre las dos "figuras" mar) y la ciudad de articulación más central e interna.

También en la Coruña se argumenta sobre un dueto repetido: la qeja su propia imagen, la autoestima en sí misma, aquello - que introducen o ejemplifican, sin otro paralelo, el salto de

En Málaga se cuenta cómo es a través de la "otra mirada" de lelos, la traza del camino de Ronda, que de hipotética carretera gran vialidad y la vivienda masiva. La forma urbis de la ciudad se analiza en las imbricadas relaciones entre la nueva gran avenida Lavedra - imagen "poderosa pero bastante fugaz" plasmada en el plano que el arquitecto César Cort - y el barrio de Elviña, en la ciudad un polígono residencial moderno de grandes dimensiones (en una propuesta que, lamentablemente, se quedaría en un plano rescatado de los archivos de la antigua Dirección General de Urbanismo).

Y finalmente, en Palma de Mallorca, la ciudad más madura de las cinco capitales, la supuesta atención sobre el Ensanche de Calvet (1901) se desvía hacia una operación mucho más concreta y decisiva, de manos de Gabriel Alomar. Auténtico enlace entre la nueva y la vieja ciudad, la apertura material de la Calle Jaime III es nueva y la vieja ciudad, la apertura material de la Calle Jaime Ill es obra del mismo arquitecto que anteriormente habia decidido su mas. Concretada a partir de los años 40 , esta fue una experiencia particular, por la continuidad directa entre el plan y el proyecto. Y particular, por la continuidad directa entre el plan y el proyecto. Y cial siendo la única de las reformas ejecutadas, fue la más esencial (la número 1), prueba de cómo Alomar supo "discernir cuál

En las cinco ciudades presentadas, el tema de la articulación entre la ciudad nueva y la preexistente es una cuestión mayúscula. Y las distintas respuestas presentadas son propuestas valiosas que se contraponen en muchos casos a mediocres alternativas, con fuerte presencia de la ortodoxia ingenieril. Durante décadas, la atención privilegiada a la nueva vialidad de las grandes arterias hizo que se despreciaran otros tantos temas importantes en la ciudad. El pecado fue el tomar la parte (el problema de la movilidad masiva del automóvil) por el todo (la complejidad urbana en su dimensión más diversa).

En las cinco ciudades presentadas, el tema de la articulación entre la ciudad nueva y la preexistente es una cuestión mayúscula. Y las distintas respuestas presentadas son propuestas valiosas que se contraponen en muchos casos a mediocres alternativas, con fuerte presencia de la ortodoxia ingenieril.

Aunque sea en términos distintos (los coches ya ocupan menos en nuestras ciudades), la visiones sectoriales o fragmentadas siguen estando presentes en la ciudad que proyectaParceris aceró en polad, en la presentación de "En Josep Parcerisa acetó en polemizar desde la tibuna "En nuestro capaces de articular lo nuevo con los valores que ya tiene la ciudad; si no, vamos a crear "edge cities" dentro de la ciudad". a Barcelona.

i “Forma general de la ciudad", en UR 4-Trieste, Laboratorio de Urbanismo de
Barcelona, enero 1986, pp.8-18. "UR 1-El Urbanismo Urbano, Laboratorio de Urbanismo de Barcelona enero iii De título homónimo al libro, fue presentada en la ETSAB-UPC en marzo
de1991 bajo la dirección de Manuel de Sola-Murales y obtuvo la calficicación
apto cum laude. Formaron el tribunal Joan Busquets, Gianni Fabbri, Antoni
Marí Rafael Moneo y Juan lús Piñón 4 Por ejemplo, Morris, A.E.J.. 'Historia de la forma urbana', Barcelona: Gus-
tavo Gilil, 1984; Benevolo, Leonardo. 'Storia della citta''4 4 vol. Bari: Later-
za, 1993; Bacon, Edmund N. 'Design of cities'. London: Thames and Hud-
son, 1982; entre otros.

Carles Crosas es doctor arquitecto y profesor del Departamento de Urbanismo de la E.T.S.A.B.

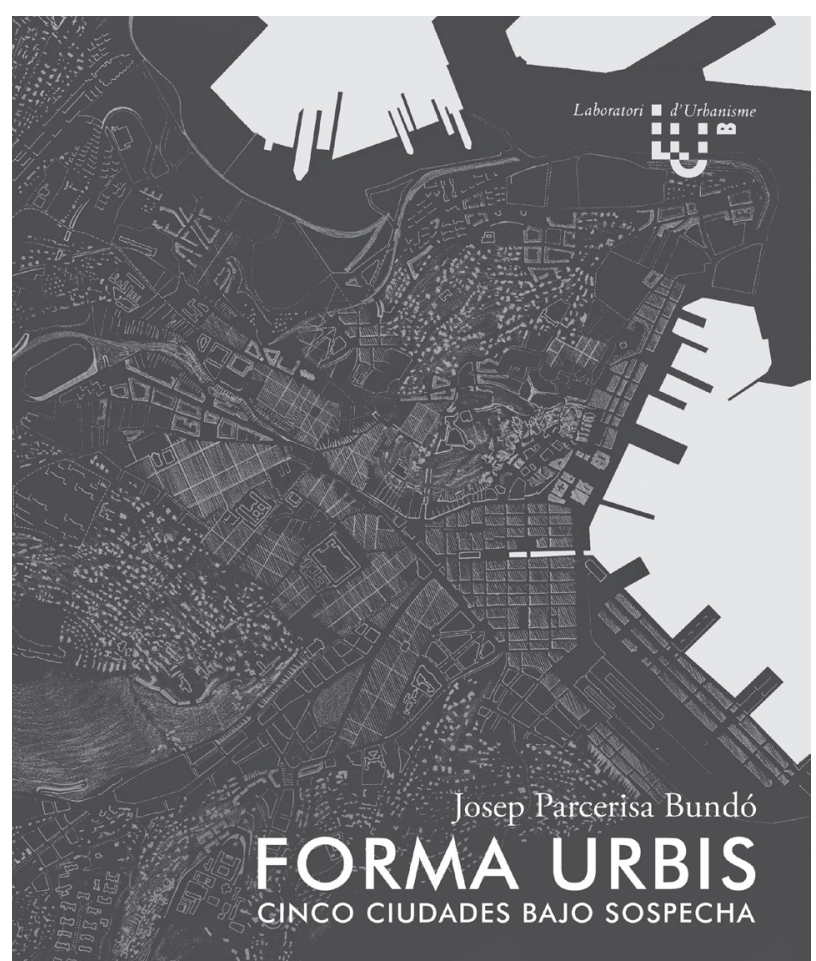

